\title{
Effectiveness of different dietary strategies in the management of obesity and obesity-related comorbidities
}

\author{
Małgorzata Jamka \\ Department of Pediatric Gastroenterology and Metabolic \\ Diseases, Poznan University of Medical Sciences \\ (iD) https://orcid.org/0000-0002-0257-6180 \\ Corresponding author: mjamka@ump.edu.pl \\ Maria Wasiewicz-Gajdzis \\ Department of Pediatric Gastroenterology and Metabolic \\ Diseases, Poznan University of Medical Sciences \\ (iD) https://orcid.org/0000-0002-7084-663X \\ Jarosław Walkowiak \\ Department of Pediatric Gastroenterology and Metabolic \\ Diseases, Poznan University of Medical Sciences \\ (iD) https://orcid.org/0000-0001-5813-5707
}

DOI: https://doi.org/10.20883/medical.e523

\begin{abstract}
Keywords: obesity, overweight, cardio-metabolic parameters, diet
\end{abstract}

Published: 2021-06-29

\begin{abstract}
How to Cite: Jamka M, Wasiewicz-Gajdzis M, Walkowiak J. Effectiveness of different dietary strategies in the management of obesity and obesity-related comorbidities. JMS. 2021 Jun. 29;90(2):e253. doi:10.20883/medical.e523
\end{abstract}

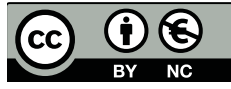

(C) 2021 by the author(s). This is an open access article distributed under the terms and conditions of the Creative Commons Attribution (CC BY-NC) licencse. Published by Poznan University of Medical Sciences

\begin{abstract}
The prevalence of obesity has been increasing worldwide; however, the optimal dietary strategy for improving anthropometric and cardiometabolic parameters remains unknown. This review discusses the effectiveness of popular diets in the management of obesity and obesity-related comorbidities. The differences among popular diets are small and associated with dietary adherence and caloric intake. The Mediterranean diet is most effective in facilitating weight loss and improving cardiometabolic parameters, although the Central European diet seems to be a good alternative.
\end{abstract}

\section{Introduction}

Obesity is one of the most vital public health issues, with the global prevalence nearly tripling between 1975 and 2016 and more than 650 million adults currently obese [1]. Diet plays an essential role in the prevention and treatment of obesity, although the optimal dietary strategy for improving anthropometric and cardiometabolic parameters remains unknown [2]. This review discusses the effectiveness of popular diets in the management of obesity and obesity-related comorbidities.

\section{Mediterranean diet}

The Mediterranean diet is based on the traditional cuisine of countries bordering the Mediterranean Sea and is characterised by a high intake of vegetables, fruits, grains, legumes and nuts. The main components of this diet also include a regular intake of fish, moderate intake of dairy products, limited intake of red meat and red wine, in addition to the use of olive oil as the main source of fat [3]. The efficacy of the Mediterranean diet has been investigated in a number randomised controlled trials [4-6] 
and meta-analyses $[2,7]$, revealing that this diet supports weight loss and improves cardiometabolic markers (e.g. glucose and insulin levels, inflammatory markers) $[6,8]$. In an umbrella review by Dinu et al. [2], the Mediterranean diet has been reported to provide the strongest and most consistent evidence of exerting a beneficial effect on anthropometric parameters (body weight and body mass index (BMI)), lipid profile, glucose and insulin homeostasis, as well as on blood pressure. Importantly, these effects seem to be independent of the caloric intake and are proportional to the dietary adherence rate $[4,5]$

\section{Central European diet}

The Central European diet is based on foods including grains (e.g. rye, oat), fish (e.g. herring), vegetables (e.g. beetroot, cabbages) and fruits (e.g. berries, apples, plums) [5]. Consequently, the diet is low in fat and high in dietary fibre and has been shown to significantly improve body weight, waist circumference, visceral fat, metabolic and atherosclerosis parameters. Moreover, the effectiveness of the Central European diet seems to be similar to the Mediterranean diet $[5,9]$.

\section{DASH diet}

The dietary approaches to stop hypertension (DASH) diet is characterised by a high intake of vegetables, fruits, whole grains and low-fat dairy products, with a moderate intake of fish, poultry and nuts and a high intake of dietary fibre, calcium, magnesium and potassium. Furthermore, it includes a low intake of sodium and fat [10]. The DASH diet has been designed to control hypertension [11]. However, the diet also helps to reduce body weight [12] and decreases the risk of cardiovascular diseases [13]. In their umbrella review, Dinu et al. [2] found suggestive evidence that the DASH diet could improve weight and blood pressure. Additionally, according to a meta-analysis by Soltani et al. [12], the DASH diet is more effective in body weight reduction than other low-calorie diets, therefore, it is thought to be a good choice with regard to obesity management.

\section{Vegetarian diet}

A plant-based diet focuses on foods of plant origin comprising a high intake of fruits, vegetables, grains, legumes, nuts and oils. Depending on the type of diet, dairy products, eggs and fish may be included or excluded [14]. Recently, it has been suggested that a vegetarian diet is more effective in body weight reduction than a nonvegetarian diet, although the effectiveness may vary depending on the type of diet. In their metaanalysis, Huang et al. [15] demonstrated a significant weight reduction in subjects consuming a vegan diet and a lacto-ovo-vegetarian diet. However, a recent umbrella review has reported this diet to have a low effectiveness in reducing cholesterol and glucose levels, blood pressure and anthropometric parameters [2], possibly due to the high variability among vegetarian diets.

\section{Low glycaemic index diet}

Reducing the glycaemic index may play a crucial role in the prevention and treatment of obesity. A low-glycaemic-index diet can regulate anthropometric parameters (e.g. BMI), promote satiety and reduce food intake, as well as reduce postprandial insulin secretion, affect insulin sensitivity and maintain glucose levels within the normal range [16]. Compared to a high-glycaemic-index diet, not only does a low-glycaemic-index diet reduce body weight, but it also affects body composition [17]. Nevertheless, the umbrella review only provided suggestive evidence of a reduction in anthropometric parameters following this diet and contrasting evidence with regard to its effect on lipid and glucose levels, as well as on blood pressure [2].

\section{Ketogenic diet}

The ketogenic diet is a type of low-carbohydrate diet, in which carbohydrate intake is limited to $5-10 \%$ of the total daily dietary requirements [18]. The diet is employed in epilepsy, Alzheimer's disease [18], or autism [19]. A recent meta-analysis has also reported a ketogenic diet to be more effective in improving metabolic and anthropometric parameters in obese subjects than a low- 
fat diet [20]. However, in another meta-analysis, Lee et al. [21] found no effect of combined exercises and ketogenic diet on body composition, fasting glucose and cholesterol levels. Additionally, the long-term use of the diet may be associated with an increased risk of various chronic diseases. In fact, Mazidi et al. [22] observed that participants with the lowest carbohydrate intake have the highest risk of overall mortality, as well as cardiovascular disease and cancer mortality. Moreover, several adverse effects were reported, including constipation, headache, diarrhoea, malaise and rash [23].

\section{High-protein diet}

A high-protein diet is defined as a diet in which at least $20 \%$ of energy is obtained from protein [24]. Mitra et al. [25] reported that in comparison with a standard diet, a high-protein diet significantly reduces anthropometric parameters (body weight, BMI, waist circumference, fat mass and percentage of body fat), insulin resistance, and C-reactive protein levels. Furthermore, de Luis et al. have reported a beneficial effect of a highprotein diet on anthropometric and metabolic parameters [26]. Such a positive effect of the diet on the abovementioned parameters is a consequence of the diet-induced diuresis, and is associated with glycogen mobilisation and loss of appetite. However, it should be noted that a longterm use of this diet may cause renal, bone and hepatic abnormalities [24].

\section{Conclusions}

Studies on the effectiveness of different dietary strategies in the management of obesity and obesity-related complications have shown heterogeneous findings. The differences among popular diets are small and associated with dietary adherence and caloric intake. Nevertheless, most evidence has supported the effectiveness of the Mediterranean diet in facilitating weight loss and improving cardiometabolic parameters. In view of the recent data, the Central European diet could be a good alternative to the Mediterranean diet, at least in Central European countries.

\section{Acknowledgements}

\section{Contributors}

M.J. wrote the manuscript. M.W.G. discussed the manuscript. J.W. commented on the manuscript. All authors reviewed and approved the final manuscript.

\section{Conflict of interest statement}

The authors declare no conflict of interest

\section{Funding sources}

There are no sources of funding to declare.

\section{References}

1. World Health Organization. Obesity and overweight [Internet]. 2020 [cited 2021 Apr 28]. Available from: https://www.who.int/news-room/fact-sheets/ detail/obesity-and-overweight

2. Dinu M, Pagliai G, Angelino D, Rosi A, Dall'Asta M, Bresciani L, et al. Effects of popular diets on anthropometric and cardiometabolic parameters: An umbrella review of meta-analyses of randomized controlled trials. Adv Nutr. 2020 Jul;11(4):815-33. doi: 10.1093/advances/nmaa006.

3. Davis C, Bryan J, Hodgson J, Murphy K. Definition of the Mediterranean diet: A literature review. Nutrients. 2015 Nov;7(11):9139-53. doi: 10.3390/nu7115459.

4. Meslier V, Laiola M, Roager HM, de Filippis F, Roume $\mathrm{H}$, Quinquis $\mathrm{B}$, et al. Mediterranean diet intervention in overweight and obese subjects lowers plasma cholesterol and causes changes in the gut microbiome and metabolome independently of energy intake. Gut. 2020 Jul;69(7):1258-68. doi: 10.1136/ gutjnl-2019-320438.

5. Bajerska J, Chmurzynska A, Muzsik A, Krzyżanowska $P$, Mądry E, Malinowska AM, et al. Weight loss and metabolic health effects from energy-restricted Mediterranean and Central-European diets in postmenopausal women: A randomized controlled trial. Sci Rep. 2018 Dec;8(1):11170. doi: 10.1038/s41598018-29495-3.

6. Panunzio M, Caporizzi R, Antoniciello A, Cela E, Ferguson L, D'Ambrosio P. Randomized, controlled nutrition education trial promotes a Mediterranean diet and improves anthropometric, dietary, and metabolic parameters in adults. Ann Ig. 2011 Jan-Feb;23(1):1325.

7. Ge L, Sadeghirad B, Ball GDC, da Costa BR, Hitchcock CL, Svendrovski A, et al. Comparison of dietary macronutrient patterns of 14 popular named dietary programmes for weight and cardiovascular risk factor reduction in adults: Systematic review and network meta-analysis of randomised trials. BMJ. 2020 Apr;369:370:m3095. doi: 10.1136/bmj.m696.

8. Esposito K, Kastorini CM, Panagiotakos DB, Giugliano D. Mediterranean diet and weight loss: Meta-analysis of randomized controlled trials. Metab Syndr Relat Disord. 2011 Feb;9(1):1-12. doi: 10.1089/ met.2010.0031.

9. Duś-Żuchowska M, Bajerska J, Krzyżanowska $\mathrm{P}$, Chmurzyńska A, Miśkiewicz-Chotnicka A, Muzsik A, et al. The Central European diet as an alternative to the Mediterranean diet in atherosclerosis prevention 
in postmenopausal obese women with a high risk of metabolic syndrome - a randomized nutrition-al trial. Acta Sci Pol Technol Aliment. 2018 Dec; 17(4):399407. doi: 10.17306/J.AFS.0593.

10. Karanja NM, Obarzanek E, Lin PH, McCullough ML, Phillips KM, Swain JF, Champagne CM, Hoben KP. Descriptive characteristics of the dietary patterns used in the Dietary Approaches to Stop Hypertension Trial. DASH Collaborative Research Group. J Am Diet Assoc. 1999 Aug;99(8 Suppl):S19-S27. doi: 10.1016/ s0002-8223(99)00412-5.

11. Karanja N, Erlinger TP, Pao-Hwa L, Miller ER, Bray GA. The DASH diet for high blood pressure: From clinical trial to dinner table. Cleve Clin J Med. 2004 Sep;71(9):745-53. doi: 10.3949/ccjm.71.9.745.

12. Soltani S, Shirani F, Chitsazi MJ, Salehi-Abargouei A. The effect of dietary approaches to stop hypertension (DASH) diet on weight and body composition in adults: A systematic review and meta-analysis of randomized controlled clinical trials. Obes Rev. 2016 May;17(5):442-54. doi: 10.1111/obr.12391.

13. Fitzgerald KC, Chiuve SE, Buring JE, Ridker PM, Glynn RJ. Comparison of associations of adherence to a Dietary Approaches to Stop Hypertension (DASH)-style diet with risks of cardiovascular disease and venous thromboembolism. J Thromb Haemost. 2012 Feb;10(2):189-98. doi: 10.1111/j.15387836.2011.04588.x.

14. Tuso PJ, Ismail MH, Ha BP, Bartolotto C. Nutritional update for physicians: plant-based diets. Perm J. 2013 Spring;17(2):61-6. doi: 10.7812/TPP/12-085.

15. Huang RY, Huang CC, Hu FB, Chavarro JE. Vegetarian diets and weight reduction: A meta-analysis of randomized controlled trials. J Gen Intern Med. 2016 Jan;31(1):109-16. doi: 10.1007/s11606-015-3390-7.

16. Juanola-Falgarona $M$, Salas-Salvadó J, IbarrolaJurado N, Rabassa-Soler A, Díaz-López A, GuaschFerré $M$, et al. Effect of the glycemic index of the diet on weight loss, modulation of satiety, inflammation, and other metabolic risk factors: A randomized controlled trial. Am J Clin Nutr. 2014 Jul;100(1):27-35. doi: 10.3945/ajcn.113.081216.

17. Abete I, Parra D, Martinez JA. Energy-restricted diets based on a distinct food selection affecting the glycemic index induce different weight loss and oxidative response. Clin Nutr. 2008 Aug;27(4):545-51. doi: 10.1016/j.clnu.2008.01.005.

18. Westman EC, Mavropoulos J, Yancy WS, Volek JS. A review of low-carbohydrate ketogenic diets. Curr
Atheroscler Rep. 2003 Nov;5(6):476-83. doi: 10.1007/ s11883-003-0038-6.

19. Rajczewski A, Gibas-Dorna M. Ketogenic diet as possible therapy of autism spectrum disorder - review and implication. JMS [Internet]. 2019 Mar;87(4):21824. doi: 10.20883/jms. 297.

20. Choi YJ, Jeon SM, Shin S. Impact of a ketogenic diet on metabolic parameters in patients with obesity or overweight and with or without type 2 diabetes: A meta-analysis of randomized controlled trials. Nutrients. 2020 Jul;12(7):2005. doi: 10.3390/ nu12072005.

21. Lee HS, Lee J. Effects of combined exercise and low carbohydrate ketogenic diet interventions on waist circumference and triglycerides in overweight and obese individuals: A systematic review and metaanalysis. Int J Environ Res Public Health. 2021 Jan;18(2):828. doi: 10.3390/ijerph18020828.

22. Mazidi M, Katsiki N, Mikhailidis DP, Sattar N, Banach M. Lower carbohydrate diets and all-cause and cause-specific mortality: A population-based cohort study and pooling of prospective studies. Eur Heart J. 2019 Sep;40(34):2870-9. doi: 10.1093/eurheartj/ ehz174.

23. Yancy WS, Olsen MK, Guyton JR, Bakst RP, Westman EC. A low-carbohydrate, ketogenic diet versus a low-fat diet to treat obesity and hyperlipidemia: A randomized, controlled trial. Ann Intern Med. 2004 May;140(10):769-77. doi: 10.7326/0003-4819-14010-200405180-00006.

24. St. Jeor ST, Howard B v., Prewitt TE, Bovee V, Bazzarre $\mathrm{T}$, Eckel RH. Dietary protein and weight reduction: A statement for healthcare professionals from the nutrition committee of the council on nutrition, physical activity, and metabolism of the American Heart Association. Circulation. 2001 Oct;104(15):1869-74. doi: 10.1161/hc4001.096152.

25. Mitra SR, Tan PY. Effect of an individualised highprotein, energy-restricted diet on anthropometric and cardio-metabolic parameters in overweight and obese Malaysian adults: A 6-month randomised controlled study. Br J Nutr. 2019 May;121(9):1002-17. doi: 10.1017/S0007114519000345.

26. de Luis DA, Izaola O, Aller R, de La Fuente B, Bachiller $\mathrm{R}$, Romero $\mathrm{E}$. Effects of a high-protein/low carbohydrate versus a standard hypocaloric diet on adipocytokine levels and insulin resistance in obese patients along 9 months. J Diabetes Complications. 2015 Sep;29(7):950-4. doi: 10.1016/j. jdiacomp.2015.06.002. 